\title{
Systematic improvement of customer satisfaction for passengers with special mobility needs
}

\author{
L. Schnieder ${ }^{1}$, A.-M. Ademeit ${ }^{1}$, M. Barrilero ${ }^{1}$, N. Schlueter ${ }^{2}$, \\ J.-P. Nicklas ${ }^{2}$, P. Winzer ${ }^{2}$, B. Starzynska ${ }^{3}$, A. Kujawińska ${ }^{3}$ \\ \& J. Diakun ${ }^{3}$ \\ ${ }^{1}$ German Aerospace Center, \\ Institute of Transportation Systems, Germany \\ ${ }^{2}$ Research Group Products Safety and Quality Engineering, \\ Bergische Universität, Germany \\ ${ }^{3}$ Faculty of Mechanical Engineering and Management, \\ Poznan University of Technology, Poland
}

\begin{abstract}
Public transport operators have to focus on a public transport system, which is inclusive and fair to all groups of society. This requires a new holistic approach reflecting the user and the service provider perspectives. The overall objective is an unrestricted use of a fully integrated cross modal public transportation along the complete mobility chain. Unrestricted use of the public transport system can be facilitated with travel assistance applications for smartphones. In addition to this, every mobility-chain needs to be accompanied by an information chain. The information provided needs to be up to date, relevant to the specific context of the user, correct and understandable. This paper presents the innovative concept of the transnational project "accessible and inclusive mobility for all with individual travel assistance" (aim4it). The project aims towards a holistic travel companion design, which provides value-added services for passenger with special mobility needs. The assistance functions are accompanied by suitable evaluation algorithms for customer feedback. An innovative systematic evaluation of customer feedback allows for continuous improvement activities of the public transport operators. Results of the project will be practically
\end{abstract}


demonstrated in close cooperation with the local public transport operators in the cities of Vienna (Austria) and Karlsruhe (Germany).

Keywords: continuous improvement, service quality, travel assistance.

\section{Motivation}

The number of elderly people and people with restricted mobility and sensual restrictions is constantly increasing. Public transport has considerable potential to gain and retain customers in this population segment. Demographic change raises the demand for assistance services in the coming years. But how to gain knowledge about changes in customer satisfaction and demands continuously so that services can be adopted effectively? How to create an individual service for people that have specific demands regarding their special kind and degree of mobility restriction or sensual restriction? This article points out the demands for individual travel assistance for these customers. It also explains the lack of possibilities in the current state of the art regarding the design of customer oriented public transportation services based on out-of-date methods like customer satisfaction measurements. In the following, the design of an innovative customer satisfaction measurement concept that is embedded in the travel assistance application will be described. The potentials and next steps for deploying this system are considered.

\section{Value-added services provided by travel assistance}

Today public transportation faces the demands of a barrier-free, cross modal service as the number of elderly people and people with special mobility needs is constantly increasing. In order to allow an active and independent use of public transport by people with special mobility needs two challenges have to be considered:

a) a travel assistance to fulfil individual needs of people with restricted needs and

b) the possibility of continuously gathering customer demands and satisfaction in short time in order to improve services immediately.

The project aim4it focusses on these two problems. It provides a concept for gathering customer satisfaction on a permanent basis instead of only carrying out customer surveys every five years as demanded by the European standard for service quality definition in public transportation [1]. Furthermore, it conducts research to provide assistance functions based on internet-based real-time information services. The provided travel assistance functions will be further described below. Afterwards the customer feedback function will be explained in more detail.

\section{1 (Re-)routing function}

One focus of the project aim4it is to supply alternative routing for passengers on the basis of real time data. This process takes into account real-time data (e.g. 
delays) as well as disruption notifications. If previously calculated routes become impracticable, the route is recalculated in its entirety (rerouting). Two different routes will be supplied. (a) a route calculated on the basis of planned data, including disruption notifications. (b) a practicable alternative route calculated on the basis of actual data. In case re-routing has an impact on requests for bus driver assistance and/or requests for passenger information these will be updated or cancelled accordingly.

\subsection{Request for bus driver assistance}

With the request for bus driver assistance it will become easier for passengers with restricted mobility or sensual restrictions to use public transport. In order to have access to the assistance service for their trip, passengers must make a reservation with the aim4it travel assistance application on their smartphone prior to their trip. With this service the bus driver awaits a passenger with restricted mobility at one previously defined station and helps to board the vehicle. At the destination station the bus driver helps the passenger with restricted mobility or sensual restrictions to alight from the vehicle.

\subsection{Request for connection protection}

Within a public transport network only some of the wide range of trips will be direct connections. Often routes from the start to the final destination require interchanges between different vehicles. In order to provide a dependable service to its passengers transport operators directly monitor connections so that connecting vehicles can wait for the passengers of the feeding vehicle if needed. The aim4it request for connection protection takes into account that passengers with restricted mobility or sensual restrictions need a longer time to transfer to the waiting vehicle. With this service the passengers will receive information that their connection will be definitely guaranteed when they are still on board their feeder vehicle. On the other hand connections can be cancelled in case they are no longer required (e.g. due to re-routing) so that direct passengers in the connecting vehicle do not suffer from delay. Of course the bus driver of the receiving bus will be informed about the required prolonged waiting time at the interchange station.

\subsection{In-vehicle passenger information}

Based on IP-based communication in public transport the project aim4it will introduce wireless communication between the aim4it smartphone app and the public transport vehicle [2]. By doing so, waiting passengers can recognise whether the approaching vehicle is the one for which they are waiting. On-board of the vehicle, additional information such as the line number, direction of travel, route and stop sequence, up-to-date information helping passengers to catch connecting services as well as deviations from the scheduled timetable can be sent from the vehicle to smartphone application. 


\subsection{Incident information in sign language}

With the travel assistance application passengers receive comprehensive support covering their entire journey. All passengers have access to detailed and reliable information throughout their journey. In order to provide these benefits to passengers with sensory restrictions the information made available to the passengers must be appropriate to various degrees of ability. Barrier-free passenger information includes that the media used to supply the information is free from barriers. It is crucial to present passenger information in the most barrier-free manner as possible. In the aim4it project special attention is paid to the demands of hearing-impaired or deaf passengers. Since this group of passengers has difficulties in deciphering complex linguistic structures passenger information will be provided by sign language videos [3].

\subsection{Feedback function}

With the aim4it feedback function passengers with sensory restrictions and/or restricted mobility can be actively involved in continuous improvement of the barrier-free public transport system. Available assessments and passenger opinions on the provided assistance functions are valuable information for the public transport operator. This allows public transport operators to set the right priorities for the adaptation of existing facilities and services to the requirements of passengers with restricted mobility or sensory restrictions. Furthermore their demands will be comprehensively taken into account in the design of public transport systems as well as the planning of public transport operations. In order to do so actual state of the art customer satisfaction measurement concepts have to be enhanced and combined with real-time IT-technology.

\section{Customer satisfaction measurement in public transport}

The disadvantages of current measurement concepts for customer satisfaction will be explained in section 3.1. For a description of the innovative concept of measuring customer satisfaction refer to section 4 .

\subsection{Current practice of customer satisfaction measurement of people with special needs in public transport}

Based on an inquiry of the project partners on actual customer satisfaction methods and continuous improvement concepts in public transportation the enhancements and adaption of services for people with special needs is based on standard quality management procedures. Based on Deming's PDCA-Cycle (Plan-Do-Check-Act) [4] the continuous improvement is initiated by customer surveys that are carried out at least every five years. By using focus groups [5] the demands of passengers with special needs are elicited, followed by the subsequent definition of measures how to improve the fulfilment of customer demands by new service designs. The improved services will be tested and evaluated by the focus groups and eventually the improved services are 
implemented into the public transportation system. The primary disadvantage is that this approach is not process-oriented. Customer satisfaction is only measured at discrete points of time and not continuously. For this reason a new measurement concept for customer satisfaction in the public transport domain was developed in the project VeRSiert [6]. This innovative concept is processoriented and can be carried out continuously as demanded in the quality management standard ISO 9000 [7]. It also fulfils criteria like customerorientation, application of different kind of survey methodologies, and trend analysis $[8,9]$. The overall methodical approach outlined in $[8,10]$ consists of eight consecutive steps.

- In a first step a qualitative analysis is performed to gather all relevant processes, responsibilities, resources and knowledge about the crossmodal public transportation system.

- The second step is the design of a service blueprint. This allows to get an overview about all services from the passengers' point of view [11]. A graphical representation of the service process and its activities is the result of this step.

- The third step is the identification of the contact points between the passenger and the public transport operator. This includes all process steps performed by the service which can be perceived by the passenger.

- The fourth step is the identification of performance indicators which can be linked to the previously defined contact points.

- The fifth step is the creation of a performance cluster which relates performance to the party responsible (as in public transport several public transport operator contribute to the service perceived by the passenger).

- The sixth step is the set-up of a generic data base. The previously defined performance clusters will be mapped into a data base.

- The seventh step is the preparation and execution of customer surveys to determine the previously defined performance indicators.

- The eighth step is a continuous data analysis which provides output for continuous improvement projects.

Certainly one disadvantage has to be considered, as the measurement concept is not implemented into public transportation information systems. In order to provide a holistic system-view with real-time information and in situ customer satisfaction measurement the concept has to be integrated into those information systems. Furthermore, those information systems have to provide passenger information services to the smartphones of the customers. This allows gathering real-time data of travel behaviour as well as additional feedback given by the passenger at specific points of contact along the service [12]. Therefore in the next section it will be pointed out how aim4it adapts this concept and integrates it into a real-time passenger information system for public transportation. By doing this continuous feedback and customer satisfaction 
measurements can be achieved in order to continuously improve service quality in public transportation based on actual data.

\subsection{Customer and process-oriented concept for implementing continuous measurement of satisfaction by using real-time IT-technology}

In order to achieve an integration of the continuous customer satisfaction measurement into public transportation information systems the concept described in the previous section has to be adopted. First of all the contact points are no longer depending on the location of the customer but on the point of time in the service process. This is caused by the fact that smartphones and their services offered via the application software can be used everywhere. The individual services and therefore the customer satisfaction mainly depend on the chronological sequence of travelling and the passage of the identified contact points. Relevant performance indicators are related to the contact points and need to be observed from the view of the functions the value-added services should provide to the customer. Other aspects that need to be considered are the complexity of public transportation information systems and their standards as well as the design of a cross-modal service and feedback application. In order to set up such a system, the procedures for IT-systems have to be mapped to the concept. Most important aspects regarding these procedures are the use of the same terms and modelling along the whole system design process in order to avoid failures and misunderstandings [13]. The adapted concept is shown in Figure 2.

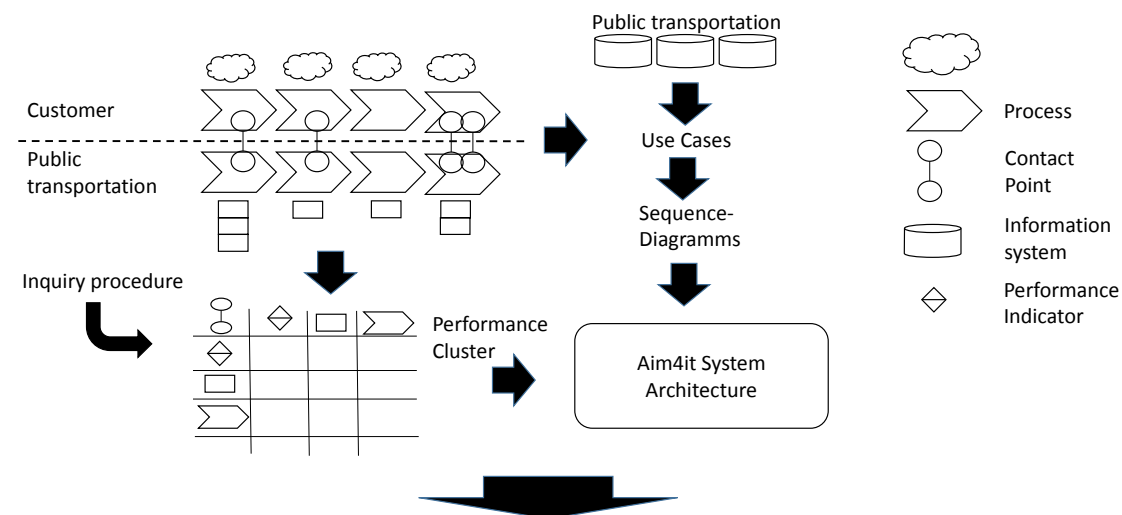

Customer satisfaction measurement concept in real-

time for mass transportation

Figure 1: Customer and process-oriented concept for implementing continuous measurement of satisfaction by using real-time ITtechnology.

The starting point is the same as in the usual implementation concept for customer- and process-oriented satisfaction measurement: the customers, their 
processes and their demands. These are linked to mass transportation processes and contact points. But those contact points are detected based on the functions in service processes that are needed in order to fulfil the demands and not regarding the local conditions for inquiry. The accomplished service blueprint offers input for the performance cluster. Furthermore it is used as basis for the use cases of each function that is supplemented with available information systems and standards in public transportation [3]. Based on the use cases sequence diagrams are built up and linked with each other in order to consider interdependencies of functions [14]. The sequence diagrams as well as the performance cluster and its inquiry procedure are transferred into a system architecture that enables the required service functions and the measurement of customer satisfaction regarding those service functions. The measurement concept along with its input and output parameters is discussed in the next section.

\section{Implementation of the real-time customer satisfaction measurement concept}

The aim4it travel assistance system is an example of an ITS (Intelligent Transport Systems) application for public transport. ITS applications aim to provide innovative services relating to different modes of transport and enable various users to be better informed and make safer, more coordinated and 'smarter' use of transport networks. But it also has the potential to integrate feedback functions and customer satisfaction measurement just after consuming the service. By using the aim4it smartphone application the user generates data which can be used for statistical analysis directed towards continuous improvement of service quality. In the following sections the input parameters (see sections 4.1, 4.2 and 4.3) as well as possible output in terms of results for management reports (see sections 4.4 and 4.5 ) will be discussed.

\subsection{Input: personal data of passengers}

With their registration for the aim4it services passengers leave personal data. Since deployment and use of travel assistance applications entails the processing of personal data, special attention has to be paid to data privacy issues. In the project the principles of purpose limitation of collected data as well as data minimisation (personal data shall only be processed insofar as such processing is necessary) will be applied [15]. Furthermore anonymization as one of the principles of enhancing individuals' privacy will be considered. The system design ensures that all collected data are protected against misuse, including unlawful access, alteration or loss. Personal information of the passenger (e.g. attributes such as type of disability and degree of disability as well as age and gender) helps to relate the observed feedback to different user groups in order to obtain differentiated statements about promising improvement measures. 


\subsection{Input: direct performance measures from service execution}

The execution of every one of the services generates data will be sent to and from the smartphone device. This data can serve as a kind of direct performance measurement in the sense of the European standard specifying service quality for the public transport domain [1]. With these measures the actual quality delivered by the public transport operator can be measured by using statistical matrices. In the last decade direct performance measures (DPM) have proven to be an adequate method of monitoring the actual performance of the service from operational records. DPM allow performance to be monitored and targeted against defined scales. Examples of data collected during service execution are for example information indications of passengers arriving on time, indications of passengers departing early/late from the (re)routing service. This data can be used as a DPM for the service criterion (adherence to schedule) set out in [1]. Another example is the indication of connections met which is a result of the connection protection service in connection with the (re)routing service. This can also be used to quantify actual service performance with respect to service criterion process data (e.g. successful execution of service) of the request for bus driver assistance service (can help to quantify the assistance service criterion.

\subsection{Input: results of customer satisfaction ratings}

The aim4it smartphone app allows to conduct customer satisfaction surveys (see figure 2 below). Customer satisfaction surveys are designed to assess the degree to which a customer believes his or her demands with respect to public transport services have been met [1]. These levels of satisfaction with the service provided can be compared against defined scales of quality expected by the customer. With the integration of customer satisfaction surveys into the travel assistance application surveys will be conducted and reported on a regular and timely basis. In the project aim4it customers can provide feedback using a star-rating for different categories of service quality.

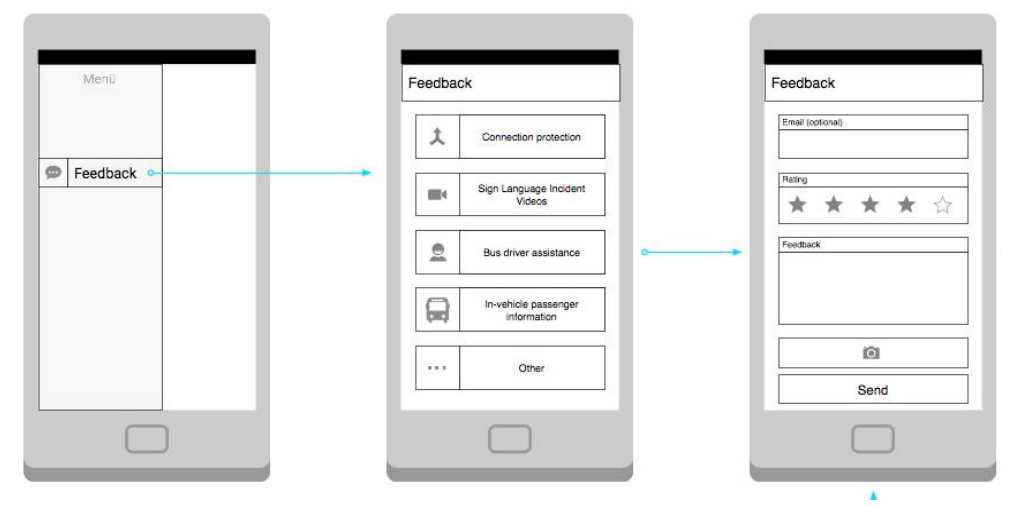

Figure 2: Mock-up of graphical user interface for customer feedback. 
The acquisition of feedback on service quality is not an end in itself. With the systematic acquisition of feedback data public transport operators strive for the implementation of a continuous improvement process of service quality (1) existing quality levels are identified, (2) areas for potential improvement identified and (3) corrective action is taken. Corrective action includes actual improvement of performance, appropriate communication to the customers as well as corrective action in the case of unacceptable performance. Input data will be analysed with respect to different criteria. Also two different kind of analysis are possible. A simple one offers KPI's to get an overview about the actual performance while the complex analysis offers widespread facts to gain knowledge about correlations of service attributes. Both analyses are exemplified in the following sub-sections.

\subsection{Output: results of simple analyses}

For each one of the above mentioned functions data can be gathered during service execution. Figure 3 shows the set of direct performance measures for the request for bus driver assistance function of the aim4it travel assistance application. The total number of requests can be further broken down to requests with a positive acknowledgement from the public transport operator and requests which had to be declined. Where requests could have been granted these happened in practice (boarding completed) or resulted in a "no show" where no boarding passenger appeared at the indicated bus station. Due to delays during operations or other operational reasons requests can be cancelled by the operator. The user can cancel requests if - for example - he or she decided to take another route by using the re-routing service.

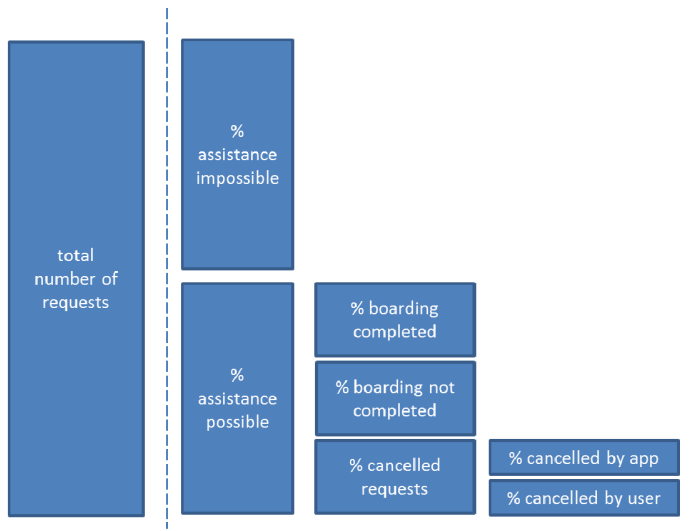

Figure 3: Process metrics from usecase "request for bus driver assistance".

The information from the direct performance measures can be linked to different customer groups. In order to do this the available data from the registration procedure can be used for the segmentation of customer groups. This 
provides further information about possible areas of improvements related to specific disabilities, degrees of disabilities and/or with respect to age and gender.

\subsection{Output: results of complex analyses}

A more complex analysis can be performed based on the customer satisfaction index. For this product attributes will be defined which have an effect on customer satisfaction. With the smartphone application a specific sample can be defined (based on available customer data). The questionnaire can be prepared. The customer is asked to evaluate each attribute and in term of their perception and expectation of performance and importance. Their satisfaction and importance is generally measured on a five-point scale (but you can use x-point scale also). Where for example: for performance: 1-means very dissatisfied, 2-somewhat dissatisfied, 3-neither dissatisfied and satisfied, 4-somewhat satisfied, 5-very satisfied. For the measurement of importance a different scale applies where 1-means is not important, 2-little importance, 3-neutral, 4-important, 5-very important. As a result of the analysis of the importance and performance ratings performed by the customer quality maps can be plotted.

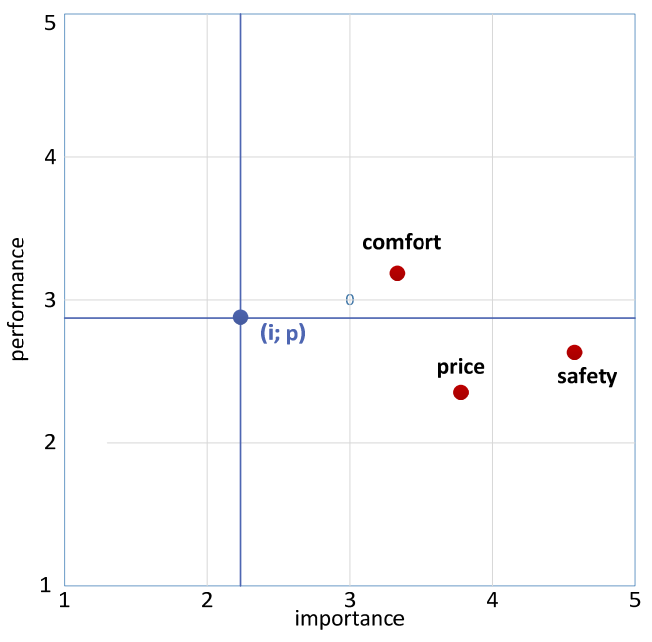

Figure 4: Importance/performance portfolio of the complex analysis [16].

The map is split into four areas as shown in figure 4. The areas of this map indicate which attributes should be kept at the current level, and which should be improved. Section I shows quality attributes whose values should be kept. Section II shows service characteristics whose attributes should be improved first (in the short time). Section III contains insignificant attributes. Public transport operators should transfer their resources to other areas. Section IV includes characteristics for improvement, but they are rated as insignificant by the passenger [16]. For this reason these service characteristics should be considered as last for service improvement. 


\section{Results, conclusion and outlook}

The project aim4it has specified services to be implemented in a travel assistance application. The aim4it system consists of several components, which are closely interlinked. The different parts of the overall system are briefly explained below: The aim4it smartphone app is the key element of the aim4it system architecture from the passenger's point of view. With the aim4it smartphone app the passenger with reduced mobility and/or sensory restrictions gets assistance in trip planning as well as the execution of the trip. Data entry and data display on the aim4it passenger user interface are designed in a user-centred way reflecting the special requirements especially of passengers with sensory restrictions (see figure 5).

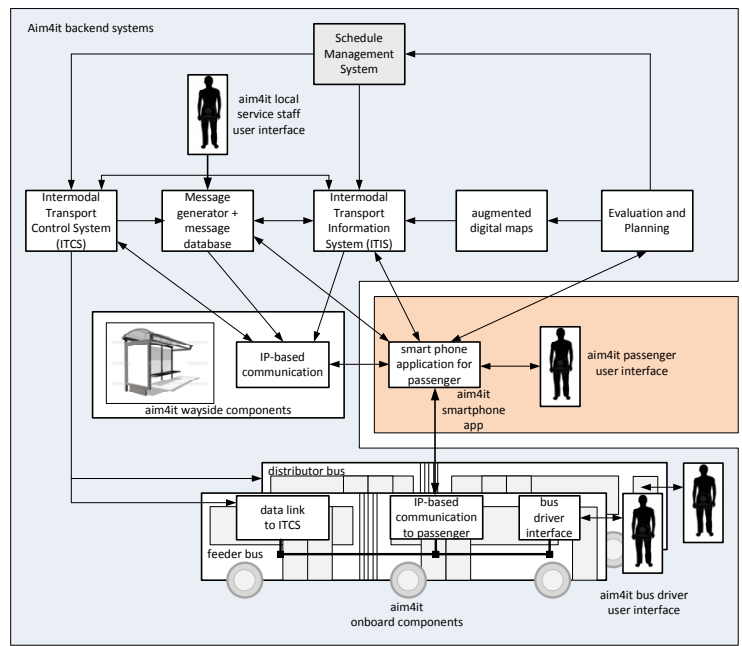

Figure 5: Overview of the aim4it system [3].

In order to continuously improve the services as well as providing the first steps to individual service designs in public transportation the feedback function of aim4it offers the possibility of a real-time based customer satisfaction measurement. Based on the data gained by this measurement concepts services and customer needs can be analysed more often and in a more detailed and flexible way and at the same time with less effort and time [6]. Right now the service blueprints and sequence diagrams as well as the inquiry tool were finalized. In the next steps the interfaces for the different system portals have to be worked out as well as the performance cluster. Results of the aim4it project will be practically demonstrated in field tests in the city of Vienna (Austria) as well as in Karlsruhe (Germany). The services will be evaluated based on the systematic acquisition of customer feedback. Feedback data acquisition will consider the methodical aspects set out in this paper. 


\section{References}

[1] EN 13816:2002: Transportation - Logistics and services - Public passenger transport- Service quality definition, targeting and measurement.

[2] Bandelin, H.; Franke, T.; Kruppa, R.; Wehrmann, A.; Weißert, D. Einheitliche Plattform für ÖPNV-Kommunikation auf gutem Weg. In: Der Nahverkehr 30 (2012) issue 7-8, p. 44.

[3] Nicklas, J.-P.; Schlüter, N.; Schnieder, L.; Winzer, P.: Entwicklung einer anforderungsgerechten Mobilitätsassistenz für in ihrer Mobilität eingeschränkte Reisende. In: Bracke, S.; Mamrot, M.; Winzer, P. (eds.): Qualitätsmethoden im Diskurs zwischen Wissenschaft und Praxis. Bericht zur GQW-Jahrestagung 2015 in Wuppertal. Aachen: Shaker Verlag, 2015.

[4] Deming, W.E.: Out of the Crisis - The Mit Press, Reprint, ISBN-13: 9780262541152, 2000.

[5] Zeithaml, V. A.; Parasumaran, A.; Berry, L. L. (1994): Alternative Scales for measuring service quality: A comparative assessment based on psychometric and diagnostic criteria; Journal of Marketing, 70 (3), pp. 201230.

[6] Reinkober, N.: VeRSiert - Sicherheit im ÖPNV bei Großveranstaltungen, 1. Auflage, Buchwerft-Verlag, Kiel, 2011.

[7] DIN EN ISO 9000, Quality Management, Beuth, 2008.

[8] Schlüter, N.; Nicklas, J.-P.; Winzer, P. (2011): Measurement of Customer Satisfaction in Business Networks. In: Jaca, C.; Mateo, R.; Viles, E.; Santos, J. (Hg.): Proceedings QMOD Conference on Quality and Service Science 2011. Pamplona, Spain: Servicios de Publicaciones Universidad de Navarra (14), S. 1321-1336.

[9] Nicklas, J.-P.; Schlüter, N.; Winzer, P.: Passenger Perception of Security A Methodical Approach for Public Mass Transportation Systems In: International Journal of Transportation, Vol. 2, No. 3 (2014), pp. 117-128, ISSN: 2287-7940 IJT, SERSC.

[10] Nicklas, J. P.; Schlüter, N.; and Winzer, P. (2012): Generic Systems Engineering for Customer Satisfaction in Networks, SDPS Conference Journal, 2012.

[11] Lovelock, C.; Witz, J.: Service Marketing - People, Technology, Strategy. New Jersey: Pearson, Vol.5, 2006.

[12] Schlüter, N.: Entwicklung einer Vorgehensweise zur Implementierung einer forderungsgerechten Kundenzufriedenheitsmessung in Unternehmensnetzwerken, In: Berichte zum Generic-Management. Band: 2013,1. Shaker, Aachen, ISBN 978-3-8440-1658-1, February 2013.

[13] Schlüter, N.: User-Competences for Virtual Reality in Early Phases of Product Development, In: Proceedings of the 16th QMOD Conference in Portoroz, Slovenia, 2013, ISBN 978-961-232-269-4, pp. 1578-1607.

[14] El-Attar, M.; Miller, J.: Constructing high quality use case models: a systematic review of current practices. In: Requirements Engineering (2012) 17:187-201. London: Springer Verlag, 2012. 
[15] Directive 2010/40/EU of the European parliament and of the Council of 7 July 2010 on the framework for the deployment of Intelligent Transport Systems in the field of road transport and for interfaces with other modes of transport. Official Journal of the European Union (L 207/1).

[16] Töpfer, A.: Konzeptionelle Grundlagen und Messkonzepte für den Kundenzufriedenheitsindex (KZI/CSI) und den Kundenbindungsindex (KBI/CRI). In: Töpfer, A. (ed.) Handbuch Kundenmanagement. Anforderungen, Prozesse, Zufriedenheit, Bindung und Wert von Kunden. 3. Vollst. Überarbeitete und erw. Auflage. Springer: Berlin/Heidelberg, 2008. 